RASĀYAN J. Chem.

Vol. 12 | No. 4 |1766 - 1773| October - December | 2019 ISSN: 0974-1496 | e-ISSN: 0976-0083 | CODEN: RJCABP

\title{
EFFECT OF ELABORATION pH ON THE ELECTROACTIVITY OF CASSAVA STARCH SOLID BIOPOLYMER ELECTROLYTE FILMS
}

\author{
Alvaro Arrieta Almario ${ }^{1, *}$, Carlos García Mogollón ${ }^{2}$ and Enrique Combatt \\ Caballero ${ }^{3}$ \\ ${ }^{1}$ Department of Biology and Chemistry, Faculty of Education and Sciences, University of Sucre, \\ P.C 700008, (Sincelejo) Colombia \\ ${ }^{2}$ Department of Agroindustrial Engineering, Faculty of Engineering,University of Sucre, P.C \\ 700008, (Sincelejo) Colombia \\ ${ }^{3}$ Faculty of Agricultural Sciences, University of Cordoba, P.C. 230001, (Monteria) Colombia \\ *E-mail : alvaro.arrieta@unisucre.edu.co
}

\begin{abstract}
In this work, a study of the effect of the $\mathrm{pH}$ used in the elaboration process of solid biopolymer electrolyte films of cassava starch on its electroactivity is presented. For the preparation process of the films, mixtures of starch, plasticizers and lithium perchlorate prepared at different $\mathrm{pH}$ values were used. Acid $\mathrm{pH}$ was achieved by the addition of hydrochloric acid and the basic $\mathrm{pH}$ with the addition of sodium hydroxide. The electroactivity of the films was evaluated by the cyclic voltammetry technique, and infrared spectroscopy was used to characterize them. The results showed that at strongly acidic $\mathrm{pH}$, the films ware brittle and had low mechanical stability, while the films prepared at moderately acid, neutral and basic $\mathrm{pH}$, the films showed good flexibility and good mechanical stability. The infrared spectroscopy allowed to establish a correlation between starch crystallinity and the elaboration $\mathrm{pH}$, indicating that at lower $\mathrm{pH}$ lower crystallinity. The results of the electrochemical studies allowed to establish that the intensities of the peaks in the signals were greater in acidic $\mathrm{pH}$ and the peak potentials had greater variability in $\mathrm{pH}$ less than 5 and greater than 9. In addition, the $\mathrm{pH}$ of processing affected the stability of the electrochemical signals. As a conclusion, it could be established that the synthesis $\mathrm{pH}$ had a great effect on the crystalline structure of the starch in the films and this affected its mechanical stability and its electrochemical response.

Keywords: Cassava, Solid Biopolymer Electrolyte, Electrochemistry, Starch, Electroactivity.
\end{abstract}

(C) RASĀYAN. All rights reserved

\section{INTRODUCTION}

Pollution is a global problem, with petroleum-derived polymers being one of the major sources of pollution, not only because of their low rate of degradation but also because of the contaminant footprint they leave during the entire production process. This situation has led many academic and industrial research centers to focus their efforts on the study and development of polymers made from biological sources, which have the capacity to be biodegradable. Since its introduction to the market in the 80 s to the present, many biopolymers have been used by the industry for the development of everyday objects and devices. The most commonly used biopolymers are cellulose extracted from timber trees, alginate obtained from algae, chitosan extracted mainly from the exoskeleton of crustaceans, starch extracted from corn and cassava. ${ }^{1-5}$

Most developed biopolymer materials are not able to conduct electric current. However, the interest of new technologies to integrate biopolymers into electrical and electronic devices have led to looking for strategies such as combining biopolymers with other materials to generate biopolymers with conductive properties. This is how cellulose $/ \mathrm{TiO}_{2}{ }^{6}$, cellulose/PEDOT ${ }^{7}$, starch/polypyrrole ${ }^{8}$, starch $/$ graphene $^{9}$, chitosan/polyaniline ${ }^{10}$, among others have been produced.

Rasayan J. Chem., 12(4), 1766-1773(2019)

http://dx.doi.org/10.31788/RJC.2019.1245302

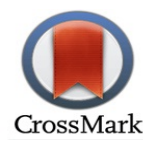


RASĀYAN J. Chem.

Vol. 12 | No. 4 |1766 - 1773| October - December | 2019

Recently, the synthesis of some biopolymers with conductive properties based on $\operatorname{starch}^{11}$, pectin ${ }^{12}$, cellulose $^{13}$, keratin ${ }^{14,15}$, has been reported in the literature. The driving mechanism in these biopolymers is given by the transport of charge through ions that travel along their charged polymer chains or with ionic species trapped in their matrix, so they are known as solid biopolymer electrolytes (SBE). ${ }^{16}$

The solid biopolymer electrolytes are a new class of materials that have technologically desirable properties, among the most interesting are its good stability, excellent conductivity, electroactivity, biodegradability, mechanical resistance and flexibility, among others. These properties have made them candidates for applications such as batteries, electroluminescent devices, solar panels, artificial muscles and smart windows. ${ }^{17-21}$

A solid biopolymer electrolyte made from cassava starch has been recently reported. ${ }^{11}$ This material has shown to have a rich electrochemical activity by presenting several oxidation-reduction processes that allow it to be attractive for use in electrochemical devices. Some publications have analyzed the effect of plasticizers, electrolyte concentration and electrolyte type on the properties of solid biopolymer electrolyte from starch. However, the effect of the $\mathrm{pH}$ of synthesis has been lesser studied and much less, the effect of this parameter on its electrochemical properties. Therefore, this paper presents a study on the electroactivity of solid biopolymer electrolyte films elaborated from cassava starch synthesized at different $\mathrm{pH}$.

\section{EXPERIMENTAL}

\section{Materials}

All the reagents used (glycerol, polyethylene glycol, glutaraldehyde, sodium hydroxide, hydrochloric acid and lithium perchlorate) were of analytical quality. All solutions were prepared using ultra-pure water (milli-Q). The cassava starch was extracted in our laboratory from cassava roots.

\section{Starch Extraction}

For the extraction of the starch, $500 \mathrm{~g}$ of fresh cassava roots of the Manihot esculenta Crantz variety were used, which were washed with abundant water. Then the roots were peeled and disintegrated by liquefying with $100 \mathrm{~mL}$ of water, the paste obtained was filtered with a silkscreen three times, adding 100 $\mathrm{mL}$ of water each time. The filtrate was allowed to stand for 12 hours, the supernatant was discarded and the precipitate allowed to dry for 24 hours in an oven at $50^{\circ} \mathrm{C}$. The dried starch was sieved on a $60 \mu \mathrm{m}$ sieve to obtain a fine, bright white powder. The purity of the starch was tested by the official method of the AOAC (Association of official analytical chemists), obtaining a purity of $99.0 \%$.

\section{Preparation of Solid Biopolymer Electrolyte Films of Cassava Starch}

To prepare the solid biopolymer electrolyte films, $3 \mathrm{~g}$ of starch were dispersed in $100 \mathrm{~mL}$ of $\mathrm{pH}$ adjusted water. The $\mathrm{pH}$ adjustment of the synthesis solution was made by the addition of $\mathrm{NaOH}(0.1 \mathrm{M})$ and $\mathrm{HCl}$ $(0.1 \mathrm{M})$ to achieve solutions with $\mathrm{pH}$ of $2,4,5,7,9,10$ and 12 . The monitoring was performed with a $\mathrm{pH}$ meter YSI Multilab 410-3W. The solutions were heated with constant stirring at $75^{\circ} \mathrm{C}$ for $15 \mathrm{~min}$. The gelatinized starch was allowed to cool to room temperature and the plasticizers and the lithium salt were added; glycerol $(2 \mathrm{~g})$, glutaraldehyde $(2 \mathrm{~g})$, polyethylene glycol $(1 \mathrm{~g})$ and lithium perchlorate $(1.5 \mathrm{~g})$. The mixture was heated at $75^{\circ} \mathrm{C}$ for 15 min with constant stirring. They were then placed in Petri dishes and dried at $70{ }^{\circ} \mathrm{C}$ for 48 hours in an oven. The resulting films were allowed to stand for 24 hours before making the characterizations.

\section{Characterization of Biopolymer Solid Electrolyte Films of Cassava Starch}

The films were characterized by infrared spectroscopy (FTIR), by using a Shimadzu IRTracer 100 spectrometer equipped with ATR (attenuated total reflestance) with the diamond crystal. The spectra were recorded in a wave number range of 4000 to $600 \mathrm{~cm}^{-1}$, a resolution of $4 \mathrm{~cm}^{-1}$ and 100 scans. The electrochemical characterization was carried out with a PARSTAT 2263 potentiostat/galvanostat (Princeton Applied Research) controlled with the PowerSuite software. The cyclic voltammetry technique was used with a sweeping range of $-2 \mathrm{~V}$ to $2 \mathrm{~V}$, a sweep speed of $100 \mathrm{mV} \mathrm{s}^{-1}$ and a cell was used for measurements in solid, consisting of two stainless steel electrodes adhered to acrylic plates. Samples were cut with $1 \times 1 \mathrm{~cm}$ measurements and placed in the cell with a sandwich-type arrangement. The potentials were measured using the open circuit potential as a reference, which had a value of $0.1 \mathrm{~V}$. 
RASĀYAN J. Chem.

Vol. 12 | No. 4 |1766 - 1773| October - December | 2019

\section{RESULTS AND DISCUSSION}

During the process of making the films, the glucose units in the starch polymer chains (amylose and amylopeptin) undergo an alkilinization reaction, in which the hydroxyl $(\mathrm{OH})$ groups are dissociated. These alkoxide groups (R-O-) convert the polymer chains of starch into chains with negative charges along with their structure. ${ }^{22}$ In Fig.-1, a schematic of the charged starch polymer chains is presented. The negative charges interact with the cations in the medium, which are mostly $\mathrm{Li}$ ions from the lithium perchlorate used as "dopant". This makes it possible to obtain films of plasticized starch, capable of conducting electricity by the movement of ions through the entire polymer matrix.

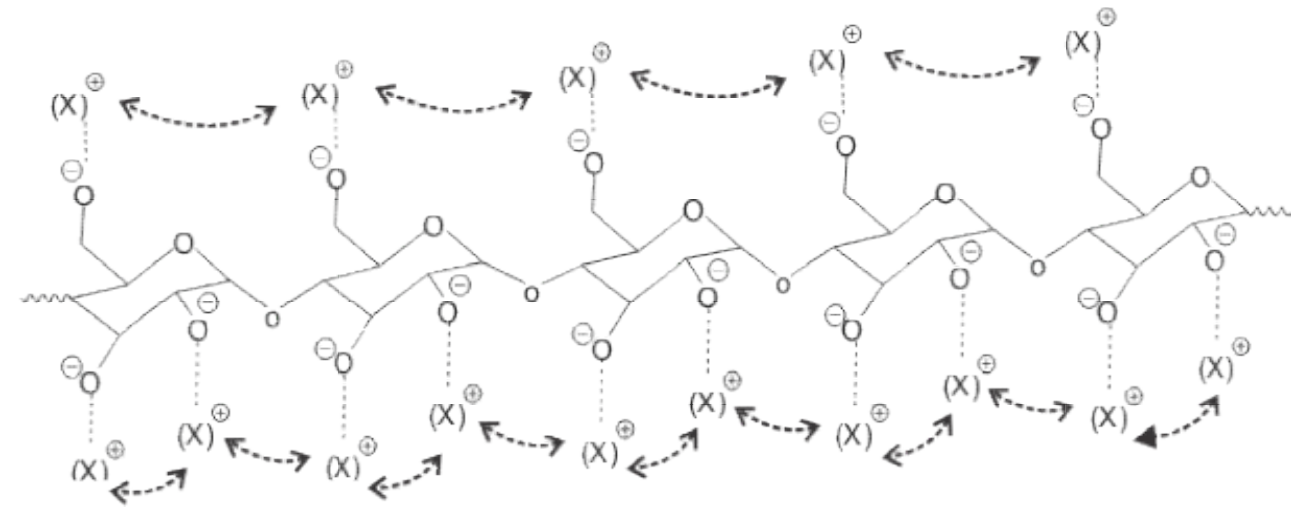

Fig.-1: Scheme of Starch Chains with Alkoxide Groups

As a result of the preparation of the films using different $\mathrm{pH}$ values, differences in appearance and stability were observed. The films prepared with $\mathrm{pH}$ less than 5 , showed an opaque yellow and fragility and breakable consistency, while the films prepared at $\mathrm{pH}$ greater than 5 , presented greater transparency and mechanical stability; they did not present breaks or fragility during their handling. In Figure 2, the biopolymer solid electrolyte films of cassava starch prepared at $\mathrm{pH} 4$ and 9 are presented as an example.

The fragility and mechanical instability observed in the films prepared at $\mathrm{pH}$ lower than 5, may be due to the fact that the $\mathrm{pH}$ has a marked effect on the opening and breaking of the amylose and amylopeptin polymers of the starch. At low $\mathrm{pH}$, the chains undergo acid hydrolysis, which causes the polymer chains to open their structure and undergo fractionation, becoming shorter and presenting a less stable crystalline structure. On the other hand, moderately acidic and basic $\mathrm{pH}$ favor the opening of chains of starch molecules to a lesser degree, and do not produce hydrolysis. Therefore, chains less open are obtained, with a more stable structure.

In order to evaluate possible changes or molecular transformations in the starch polymers due to variations in the $\mathrm{pH}$ of synthesis, measurements were made with infrared spectroscopy on each of the films. The spectra recorded in all the films showed the typical pattern of polymerized starch, with the characteristic bands of this polysaccharide, which indicates that no significant transformations were generated in its composition or in the molecular structure of the polymers. On the other hand, the FTIR spectra can be used to estimate the crystallinity of the starch. It has been reported that the FTIR spectra are sensitive to variations in the conformation of the chains, crystallinity and water content in starches. ${ }^{23-}$

The region of the infrared spectrum associated with these changes is between 1300 and $800 \mathrm{~cm}^{-1}$, in this region are the bands assigned to the vibrations of C-O, C-O-C, C-H and C-O-H. Specifically, the band at $1047 \mathrm{~cm}^{-1}$ is sensitive to the crystallinity of the starch and the band at $1022 \mathrm{~cm}^{-1}$ is characteristic of amorphous starch. This allowed us to study the crystallinity indexes when establishing a relationship between the absorbance of the bands at $1047 \mathrm{~cm}^{-1}$ and $1022 \mathrm{~cm}^{-1}(\mathrm{Xc}=\mathrm{Abs} 1047 / \mathrm{Abs} 1022)$. With the increase in the crystallinity of the starch molecules the intensity of the band at $1047 \mathrm{~cm}^{-1}$ increases and the intensity of the band $1022 \mathrm{~cm}^{-1}$ decreases. Therefore, the value of Xc will be indicative of the crystallinity of the starch being higher at higher crystallinity. ${ }^{24,26}$

To evaluate the effect of $\mathrm{pH}$ of preparation on the crystallinity of the films, the Xc index calculated with the absorptions measured in the bands at 1022 and $1047 \mathrm{~cm}^{-1}$ was plotted against the $\mathrm{pH}$ values used in 
RASĀYAN J. Chem.

Vol. 12 | No. 4 |1766 - 1773| October - December | 2019

the synthesis of the films. In Fig.-3, the relationship obtained from plotting the Xc vs. pH. The polynomial relation of order 2 can be observed, which responds to the equation $\mathrm{Xc}=8 \times 10^{-4} \mathrm{pH}^{2}-6.8 \times 10^{-}$ ${ }^{3} \mathrm{pH}+0.304$ with a correlation index $\left(\mathrm{R}^{2}\right)$ of 0.9814 . This result allows establishing that as the $\mathrm{pH}$ is more acid the crystallinity of the starch in the films decreases, the reason for which rupture and cracking can occur in the films made at $\mathrm{pH}$ lower than 5.

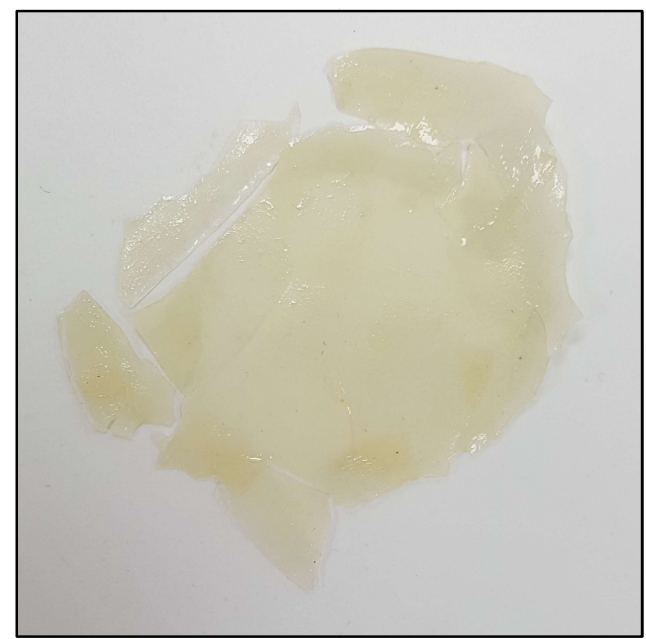

(a)

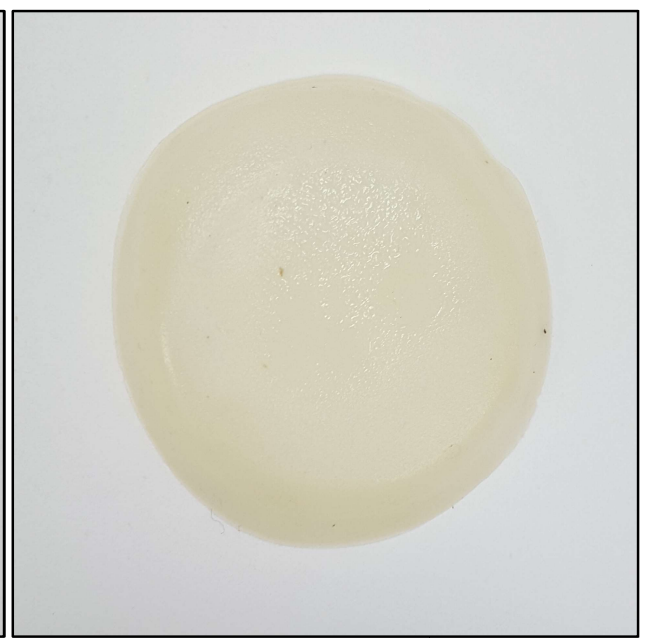

(b)

Fig.-2: Solid Biopolymer Electrolyte Films From Cassava Starch Elaborated at Different pH Values: (a) pH 4 and (b) $\mathrm{pH} 9$

The electrochemical behavior of the films was evaluated by cyclic voltammetry. For this, 50 cycles of each of the films were recorded in a potential range of $-2 \mathrm{~V}$ to $2 \mathrm{~V}$. As can be seen in Figure 4, the voltammetric curves clearly show three redox pairs, which can be attributed to the oxidation/reduction processes of the glucose units that comprise it.

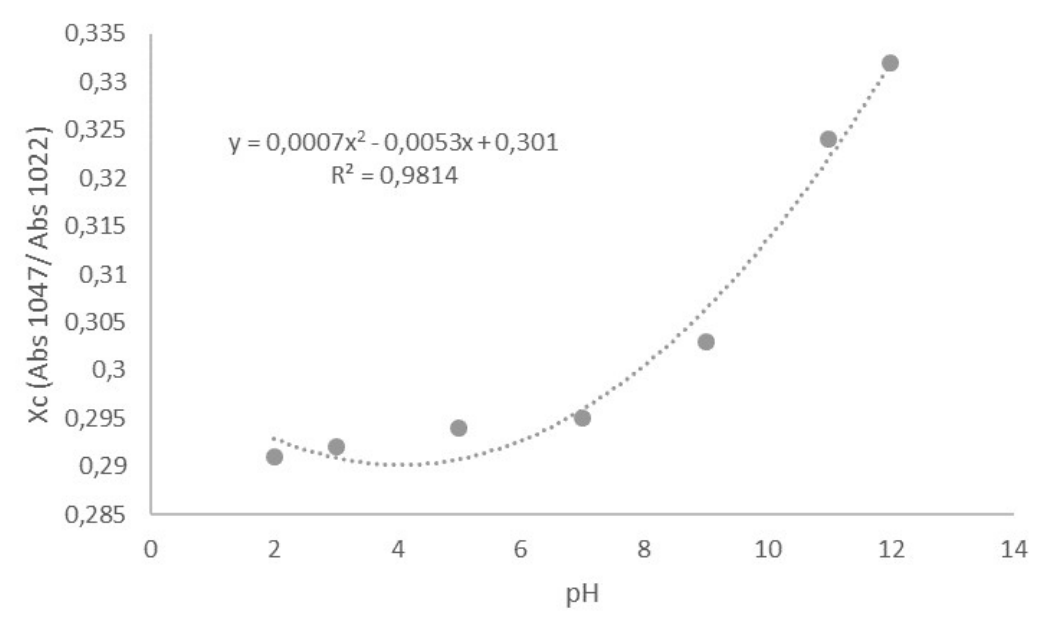

Fig.-3: Preparation pH Vs Cystallinity Index (Abs 1047 / Abs 1022) of Solid Biopolymer Electrolyte Films From Cassava Starch.

Several studies have reported the mechanisms and electrochemical reactions of oxidation and reduction of glucose molecules under different conditions. ${ }^{27-29}$ Additionally, the redox processes of dispersions of gelatinized starches of corn, banana, cassava and potato have been described and related to the three processes proper to glucose molecules. ${ }^{30}$ As reported, the first process (I) corresponds to the 
RASĀYAN J. Chem.

Vol. 12 | No. 4 |1766 - 1773| October - December | 2019

dehydrogenation of the glucose unit of the polymeric molecule in the hemiacetalic carbon 1 (C1), therefore, this first process can generate depolymerization in the chains, the second process (II) may be due to the oxidation/reduction of the hydroxyl groups of carbons 2 (C2) and $3(\mathrm{C} 3)$ and the third process (III) by the oxidation/reduction of the hydroxyl group of carbon 6 (C6).

On the other hand, it can be observed that the films have similar behavior in terms of the shape of the voltammograms. However, the stability of the signals was variable, the signals of the films were more unstable at extreme $\mathrm{pH}$ (less than 4 and greater than 11) while at neutral $\mathrm{pH}$ and basic or moderate acid (between 4 and 11), they present greater stability. The signals of the films elaborated at $\mathrm{pH} 2$ and 12, present voltammograms whose peaks of oxidation and reduction of processes I and III, decrease drastically until almost disappearing in the first 15 cycles. This may be because the oxidation/reduction reactions of the hydroxyl groups located at the ends of the chains (a process I) and the hydroxyl group of carbon 6 (C6) (process III) are quasi-reversible. What makes the redox peaks tend to disappear as the reactions are given and the number of available groups decreases. On the other hand, the peaks of process II tend to increase their intensity. This phenomenon may be due to the fact that the depolymerization of the chains produced by the reactions of the process I, decrease the crystallinity, making the carbon 2 and 3 sites more accessible. In films generated at medium $\mathrm{pH}$, this phenomenon is moderate and there are no marked differences in the growth of the peaks of process II or the decrease in the peaks of processes I and III.

It was also observed that the position of the peaks (Ep) and the intensities (Ip) in the signals, presented some variations. Table-1 shows the potentials and currents of oxidation and reduction of the processes (I, II and III) observed in the signals of each of the films.

In the voltammograms of Fig.-4, marked differences are observed in the potentials (Ep) and currents (Ip) of oxidation and reduction of the different processes. At more acidic $\mathrm{pH}$, the redox peaks are more intense; peak currents in process II is four times higher in films prepared at $\mathrm{pH}$ of 2, compared to those prepared at $\mathrm{pH}$ 12. In peaks I and III, the difference is less marked, however, it reaches double. The higher values of currents registered with the films prepared at lower $\mathrm{pH}$, may be due to the fact that the acid $\mathrm{pH}$ favors the opening of the starch chains and this allows greater areas of conduction, while at moderately acidic, neutral and basic $\mathrm{pH}$ the Polymer chains open to a lesser degree leaving encapsulated areas. Therefore, they have less ability to conduct electric current and fewer electroactive areas. On the other hand, peak potentials (Ep) present moderate variations, which can be generated by differences in the arrangement or ordering of structures due to depolymerization and variations in the crystallinity of the chains.

Table-1: Potentials (Ep) and Currents (Ip) of the Oxidation and Reduction Peaks in the Redox Processes of Polymeric Solid Electrolyte Films From Cassava Starch

\begin{tabular}{|c|c|c|c|c|c|c|c|c|c|c|c|c|}
\hline \multirow{3}{*}{$\mathrm{pH}$} & \multicolumn{4}{|c|}{ Process I } & \multicolumn{4}{|c|}{ Process II } & \multicolumn{4}{|c|}{ Process III } \\
\hline & \multicolumn{2}{|c|}{ oxidation } & \multicolumn{2}{|c|}{ Reduction } & \multicolumn{2}{|c|}{ oxidation } & \multicolumn{2}{|c|}{ Reduction } & \multicolumn{2}{|c|}{ oxidation } & \multicolumn{2}{|c|}{ Reduction } \\
\hline & Ep & Ip & Ep & Ip & Ep & Ip & Ep & Ip & Ep & Ip & Ep & Ip \\
\hline 2 & 1,58 & 253,3 & 0,67 & $-138,2$ & 0,27 & 423,6 & $-0,29$ & $-425,1$ & $-0,64$ & 174,8 & $-1,79$ & $-168,5$ \\
\hline 4 & 1,48 & 219 & 0,58 & $-157,3$ & 0,2 & 398,3 & $-0,31$ & $-377,5$ & $-0,55$ & 145,6 & $-1,53$ & -215 \\
\hline 5 & 1,5 & 201 & 0,57 & $-145,3$ & 0,22 & 385,7 & $-0,301$ & $-315,2$ & $-0,54$ & 164,3 & $-1,48$ & $-217,2$ \\
\hline 7 & 1,56 & 174,3 & 0,55 & $-132,5$ & 0,25 & 353,9 & $-0,32$ & $-304,3$ & $-0,51$ & 185,3 & $-1,45$ & $-231,2$ \\
\hline 9 & 1,55 & 156,3 & 0,53 & $-119,8$ & 0,31 & 338,4 & $-0,29$ & $-292,4$ & $-0,49$ & 204,4 & $-1,41$ & $-245,1$ \\
\hline 10 & 1,39 & 167,3 & 0,43 & -110 & 0,21 & 261 & $-0,33$ & -218 & $-0,35$ & 175 & $-1,34$ & $-235,8$ \\
\hline 12 & 1,29 & 101,1 & 0,31 & $-75,7$ & 0,18 & 141,5 & $-0,3$ & $-116,3$ & $-0,23$ & 131 & $-1,25$ & $-166,6$ \\
\hline
\end{tabular}

To analyze the effect of the synthesis $\mathrm{pH}$ on the potentials and peak currents of the redox processes of the films, the different potentials and currents of the oxidation and reduction processes versus the synthesis $\mathrm{pH}$ were plotted (figure 5). In all cases, the voltammetric signals of the third cycle were taken to avoid the variability due to the instability of the signals in the films made at $\mathrm{pH}$ less than 5 and greater than 9 . 
RASĀYAN J. Chem.

Vol. 12 | No. 4 |1766 - 1773| October - December | 2019

Figure-5a shows the behavior of peak potentials (Ep) vs. Synthesis $\mathrm{pH}$. It can be clearly observed that, at extreme $\mathrm{pH}$, lower than 5 and higher than 9 , the variations of the potentials were marked; in $\mathrm{pH}$ greater than 9, the potentials of the oxidation processes become lower and in the reductions, higher values are presented. On the other hand, at $\mathrm{pH}$ lower than 5, the oxidation potentials shift to higher potentials and the reductions to lower potentials. In the intermediate $\mathrm{pH}$, between 5 and 9 , the potentials do not show significant variations.
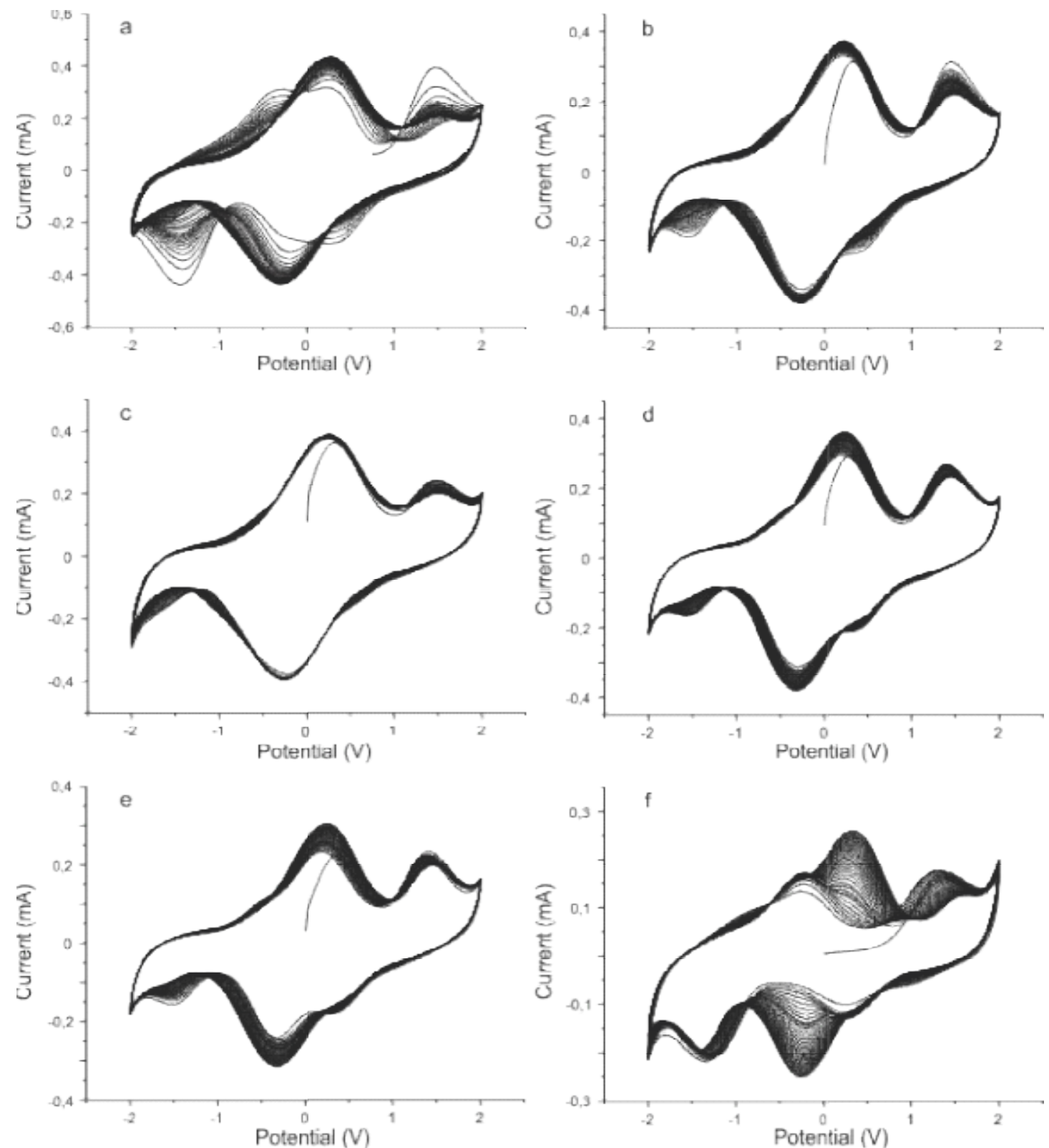

Fig.-4: Voltammetric Response of Solid Electrolyte Films From Cassava Starch Elaborated at Different pH Values: (a) $\mathrm{pH}$ 2, (b) $\mathrm{pH} 4$, (c) $\mathrm{pH}$ 7, (d) $\mathrm{pH}$ 9, (e) $\mathrm{pH} \mathrm{10,} \mathrm{(f)} \mathrm{pH} 12$

The behavior of the peak currents (Ip) as a function of the synthesis $\mathrm{pH}$ of the films is presented in Figure 5.b. It can be observed that the peak currents (Ip) showed a tendency similar to that exhibited by the peak potentials (Ep), presenting greater variability in the extreme $\mathrm{pH}$ (less than 5 and greater than 9), and values very similar to $\mathrm{pH}$ intermediate (between 5 and 9). The currents recorded with films prepared at $\mathrm{pH}$ below 5 are much higher than those recorded with films made at $\mathrm{pH}$ greater than 9 . This result is 
RASĀYAN J. Chem.

Vol. 12 | No. 4 |1766 - 1773| October - December | 2019

consistent with that observed in the studies conducted with FTIR. Due it is expected that the films with polymeric chains more open and less crystalline structure, they can be more conductive and therefore register higher current values.
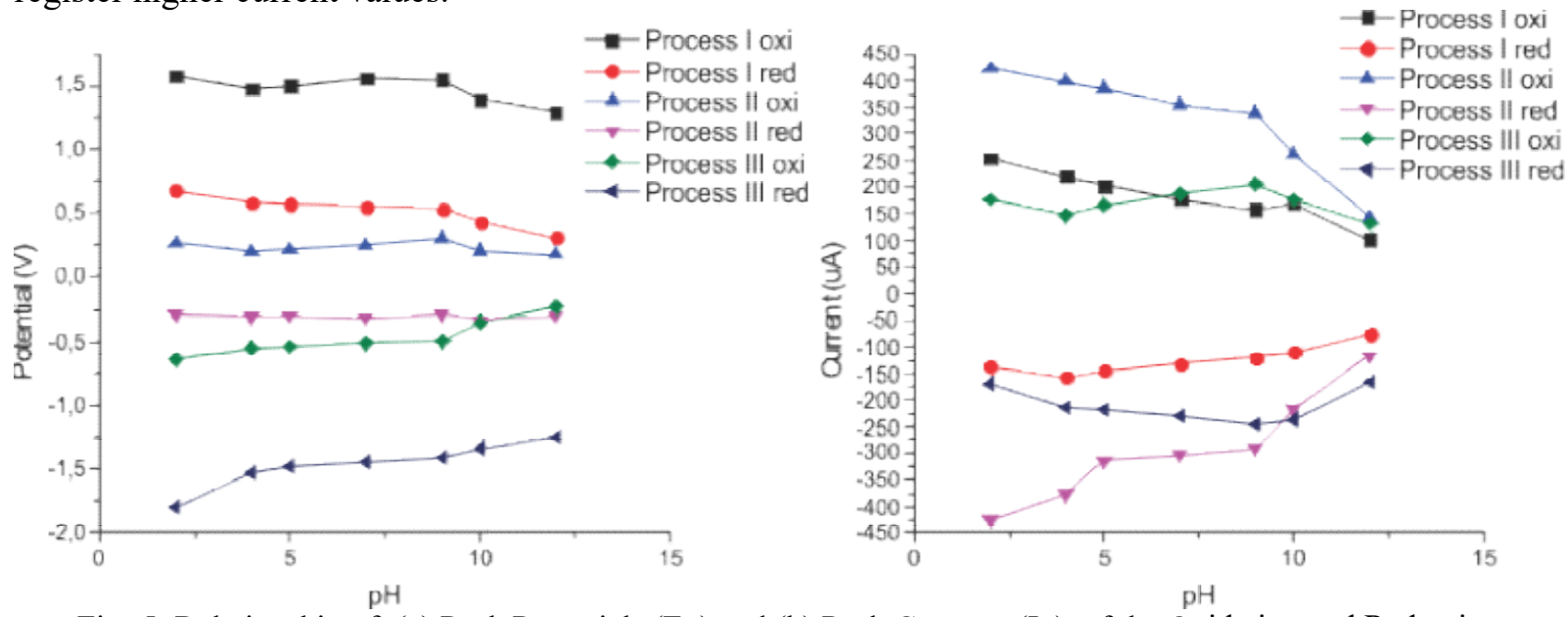

Fig.-5: Relationship of: (a) Peak Potentials (Ep) and (b) Peak Currents (Ip), of the Oxidation and Reduction Processes of Solid Electrolyte Films From Cassava Starch Elaborated at Different pH Values

\section{CONCLUSION}

Solid biopolymer electrolyte films from cassava starch were elaborated with different $\mathrm{pH}$ values $(2,4,5$, 7, 9, 10 y 12). Films made at strongly acidic $\mathrm{pH}$ (less than 5), presented fragility and mechanical instability, while those made at intermediate and basic $\mathrm{pH}(\mathrm{pH}$ greater than 5) were stable and flexible.

The studies carried out with infrared spectroscopy (FTIR-ATR), allowed to establish that the pH used in the production process of the films had a marked effect on the crystallinity of the resulting starch polymer. The acidic $\mathrm{pH}$ produces hydrolysis of the starch molecules and the depolymerization thereof. At strongly acid $\mathrm{pH}$, more open structures with shorter chains are produced, which can generate fragility and mechanical instability.

The electrochemical behavior of the films was affected by the $\mathrm{pH}$ used in the synthesis. films synthesized at extreme $\mathrm{pH}$ (less than 4 and greater than 10) showed instability in their signals. The peaks of the oxidation and reduction processes showed variations in the position and intensity when varying the synthesis $\mathrm{pH}$. Although films made with moderately acid $\mathrm{pH}$ exhibited better electrochemical behavior in terms of signal stability and peak intensities, they are much less mechanically stable, due to their cracking and brittleness caused by acid depolymerization.

\section{ACKNOWLEDGMENT}

The authors acknowledge the financial support of the University of Sucre.

\section{REFERENCES}

1. C.F. Hsieh, W. Liu, J. K. Whaley and Y.C. Shi, Trends in Food Science \& Technology, 83, 225(2019), DOI: 10.1016/j.tifs.2018.11.022

2. A. Sharma, M. Thakur, M. Bhattacharya, T. Mandal and S. Goswami, Biotechnology Reports,21, 316(2019), DOI:10.1016/j.btre.2019.e00316

3. K. Kalantari, A.M. Afifi, H. Jahangirian and T.J. Webster, Carbohydrate Polymers, 207, 588(2019), DOI:10.1016/j.carbpol.2018.12.011

4. M. Hasan, Zulfadli, M. Nazar, R.F.I. Rahmayani, G. Fajri and H. Fansuri, RasayanJ.Chem., 12(3), 1390(2019), DOI:10.31788/RJC.2019.1235326

5. S. Jyothi, Y.V. Subba Rao and P. S. Samuel Ratnakumar, RasayanJ.Chem., 12(2), 537(2019), DOI: $10.31788 /$ RJC.2019.1225000

6. A.M. ElNahrawy, A.A. Haroun, I. Hamadneh, A.H. Al-Dujaili and S. kamel, Carbohydrate Polymers, 168, 182(2017), DOI:10.1016/j.carbpol.2017.03.066 
RASĀYAN J. Chem.

Vol. 12 | No. 4 |1766 - 1773| October - December | 2019

7. A.V. Andrianov, A.N. Aleshin, A.K. Khripunov and V.N. Trukhin, Synthetic Metals, 205, 201(2015), DOI:10.1016/j.synthmet.2015.04.016

8. A.A. Arrieta and M.S. Palencia, Latin American journal of metallurgy and materials, 36(1), 26(2016).

9. S. Javanbakht and Hassan Namazi, Carbohydrate Polymers, 176, 220(2017), DOI:10.1016/j.carbpol.2017.08.080

10. A. Torvi, S. Naik and M. Kariduraganavar, Chemical Data Collections, 17-18, 459(2018), DOI:10.1016/j.cdc.2018.11.003

11. A.A. Arrieta, P.F. Gañán, S.E. Márquez and R. Zuluaga, Journal of the Brazilian Chemical Society, 22(6), 1170(2011).

12. M. Vahini and M. Muthuvinayagam, Materials Letters, 218, 197(2018), DOI:10.1016/j.matlet.2018.02.011

13. A.S. Samsudin, H.M. Lai and M.I.N. Isa, Electrochimica Acta, 129, 1(2014), DOI:10.1016/j.electacta.2014.02.074

14. M.W. Donner, M. Arshad, A. Ullah and T. Siddique, Science of The Total Environment, 647, 1539(2019), DOI:10.1016/j.scitotenv.2018.07.429

15. B. Sharma, P. Malik and P. Jain, Materials Today Communications, 16, 353(2018), DOI: $10.1016 /$ j.mtcomm.2018.07.004

16. R. Singh, P.K. Singh, V. Singh and B. Bhattacharya, Optics \& Laser Technology, 113, 303(2019), DOI:10.1016/j.optlastec.2018.12.036

17. R. Singh, A. R. Polu, B. Bhattacharya, H-W. Rhee and P. K. Singh, Renewable and Sustainable Energy Reviews, 65, 1098(2016), DOI:10.1016/j.rser.2016.06.026

18. Y. N. Sudhakar, M. Selvakumar and D. K. Bhat, An introduction of Biopolymer Electrolytes, Elsevier, Biopolymer Electrolytes, New York, p. 1,34(2018).

19. Y. E. Núñez, Á A Arrieta, J. A. Segura and S. D. Bertel, Journal of Physics: Conference Series,687, 1(2016), DOI:10.1088/1742-6596/687/1/012042

20. M. Seshu Kumar, Sk. ShahenoorBasha and M. C. Rao, Rasayan J. Chem, 11(2), 613(2018), DOI:10.31788/RJC.2018.1122082

21. S. ShashiDevi, S. UdayaLaxmi and A. SadanandaChary, Rasayan J. Chem, 11(4), 1624(2018), DOI: $10.31788 /$ RJC.2018.1144028

22. S. F. Chin, A. Azman, and S. C. Pang, Journal of Nanomaterials, 2014, 1(2014), DOI: $10.1155 / 2014 / 108359$

23. Y. Sun, Z. Wu, B. Hu, W. Wang, H. Ye, Y. Sun, X. Wang and X. Zeng, Carbohydrate Polymers, 108, 153(2014), DOI:10.1016/j.carbpol.2014.02.093

24. N. M. Vicentini, N. Dupuy, M. Leitzelman, M. P. Cereda, and P. J. A. Sobral, Spectroscopy Letters, 38(6), 749(2005), DOI:10.1080/00387010500316080

25. I. Dankar, A. Haddarah, F. E.L.Omar, M. Pujolà, F. Sepulcre, Food Chemistry, 260, 7 (2018), DOI:10.1016/j.foodchem.2018.03.138

26. J.J.G. Van Soest, H. Tournois, D. de Wit and J.F.G. Vliegenthart, Carbohydrate Research, 279, 201(1995), DOI:10.1016/0008-6215(95)00270-7

27. K. E. Toghill and R. G. Compton, International Journal of Electrochemical Science, 5(9), 1246(2010).

28. D. Kuakpetoon and Y-J. Wang, Carbohydrate Research, 341(11), 1896(2006), DOI:10.1016/j.carres.2006.04.013

29. Y-J. Wang, L. Wang, Carbohydrate Polymers,52(3), 207(2003), DOI:10.1016/S0144$8617(02) 003041$

30. C. Hernandez-Jaimes, C. Lobato-Calleros, E. Sosa, L.A. Bello-Perez, E.J. Vernon-Carter and J. Alvarez-Ramirez, Carbohydrate Polymers,124, 8(2015), DOI:10.1016/j.carbpol.2015.02.002

[RJC-5302/2019] 